\title{
Environmental taxes with heterogeneous consumers: an application to energy consumption in France
}

\author{
Helmuth Cremer \\ IDEI and GREMAQ, University of Toulouse \\ and Institut universitaire de France \\ Toulouse, France \\ Firouz Gahvari* \\ University of Illinois at Urbana-Champaign \\ Champaign, IL 61820, USA \\ Norbert Ladoux \\ IDEI and GREMAQ, University of Toulouse \\ Toulouse, France \\ March 2001 \\ Revised, February 2002
}

${ }^{*}$ We thank Don Fullerton, Larry Goulder, Gib Metcalf, Sarah West, Rob Williams, other participants in the NBER Summer Environmental Economics Workshop 2001, Amadeo Spadaro and two anonymous referees of this Journal for useful comments. We are particularly grateful to Roger Gordon for his comments and advice. 


\begin{abstract}
This paper constructs a model with four groups of households who have preferences over labor supply, consumption of polluting (energy related) and non-polluting (nonenergy) goods and emissions. It quantifies the model for the French economy and computes its optimal tax equilibria under nine second-best tax regimes. We find that redistributive role of environmental taxes require the polluting goods to be taxed at a rate much below their marginal social damage. They may even require an outright subsidy if the society values equality "a lot". Secondly, environmental taxes that have an exclusively externality-correcting role, benefit all types - although the gains are rather modest. The gains and losses become more substantial when environmental taxes have a redistributive role as well. Third, setting the environmental tax at its Pigouvian level, rather than its optimal externality-correcting-cum-redistributive level, benefits the high-income group at the expense of the low-income groups. Fourth, nonlinear taxation of polluting goods, and nonlinear commodity taxation in general, is a powerful redistributive mechanism. Fifth, introducing environmental taxes in the current French tax system, with its suboptimal income taxes, results in substantial welfare gains for the highest income group and a sizable loss for the least well-off persons.
\end{abstract}

JEL classification: H21; H23; D62

Keywords: Second-best; environmental taxes; optimal taxation; nonlinear taxes; welfare gains 


\section{Introduction}

A number of authors have recently studied the optimal tax design problem with externalities, and the structure of environmental taxes, in light of modern optimal tax theory à la Mirrlees (1971). This theory allows for heterogeneity among individuals and justifies the use of distortionary taxes on the basis of informational asymmetries between tax authorities and taxpayers. A hallmark of this literature is its inclusion of nonlinear tax instruments. [See, among others, Kaplow (1996), Mayeres and Proost (1997), Pirttilä and Tuomala (1997), and Cremer, Gahvari and Ladoux (1998).] These studies are exclusively theoretical. The empirical studies of environmental taxes, on the other hand, have remained squarely in the Ramsey tradition. As such, they typically assume identical consumers and allow for linear tax instruments only; see, e.g., Bovenberg and Goulder (1996). ${ }^{1}$ More importantly, the applied literature has in the main been concerned with welfare implications of "piecemeal" tax reforms. This approach ignores the fact that the benefits of reforming any particular tax is fundamentally linked to the way the other taxes in the system are set.

The "piecemeal" approach is thus problematic from a policy perspective. It may undermine the role that income taxation can play in offsetting the possible "regressive bias" of environmental taxes. Poterba (1991) estimates that, with few exceptions, the expenditure shares of such polluting goods as gasoline, fuel oil, natural gas and electricity decrease at all income deciles as income increases. ${ }^{2}$ This suggests that environmental taxes may entail undesired redistributive consequences. The question facing the policy makers is thus to determine how serious this problem is and how, i.e. through what tax instruments, it can best be offset.

\footnotetext{
${ }^{1}$ Most recently, Mayeres and Proost (2001) have introduced consumer heterogeneity and distributional aims. However, that paper remains within the Ramsey tradition considering only linear tax instruments.

${ }^{2}$ The exceptions are fuel oil and gasoline. The shares for fuel oil remain the same at some deciles and the consumption of gasoline increases in going from second to third decile.
} 
The purpose of this study is to examine the efficiency and redistributive power of polluting good taxes in different tax systems. The usefulness of environmental taxes must be evaluated in relation to other tax instruments that the government has at its disposal. The question of how non-environmental taxes, and particularly income taxes (whether linear or nonlinear), are set is an important one. Their optimality, or suboptimality, affect the redistributive properties of environmental taxes. To offset the potential regressive bias of environmental taxes, the government must be able to readjust its other tax instruments. The point is somewhat related to that made by the advocates of the "double-divided hypothesis" who argue that how the government spends the environmental tax revenues matter. [See Goulder (1995) for an excellent survey]. However, the emphasis that literature has put on the distinction between first- versus second-best in this regard is misplaced. As Gahvari (2002) has recently pointed out, the existence of a second dividend does not depend on this distinction. Rather, it hinges on whether or not the (second-best) tax system is optimal from a non-environmental perspective.

A second important feature of our study is our explicit recognition of the two potential roles of polluting good taxes: externality-correcting and optimal tax considerations. That taxation of polluting goods should not be based solely on environmental grounds is often ignored in the discussions of this issue. This is a serious omission that may result in misdirected policy recommendations. Whereas the negative externality properties of polluting goods call for their taxation, their "necessity" attribute calls for their subsidization. Whether polluting goods should be taxed or subsidized thus depends, in the absence of explicit emission taxes, on which effect dominates the other. Of course, the (non-environmental) efficiency costs of such taxes or subsidies also play a role here.

The third feature of our study is that it pays particular attention to tax systems that include nonlinear income taxes. This is important. Restricting income taxes to be linear, as is often done, has no basis in theoretic or policy grounds. The feasibility of 
a particular tax instrument is ultimately determined by the type of information that is available to the tax administration. To the extent that incomes are publicly observable, they can be taxed nonlinearly (and not just linearly). Consequently, there are no informational grounds for restricting income taxes to be linear. Moreover, as a policy matter, governments in all countries typically employ graduated income tax schedules. These considerations call for an examination of environmental taxes in presence of nonlinear income taxes. For the purpose of comparisons, we also consider settings with linear income taxes as well as first-best differential lump-sum taxes.

We model an economy consisting of four groups of individuals who differ in earning abilities and may differ in tastes as well. ${ }^{3}$ They have preferences over labor supply, two categories of consumer goods, "non-polluting" and "polluting", and total level of emissions in the atmosphere (a negative consumption externality). Emissions result when people consume polluting goods. We identify the consumer types, specify which goods are polluting and which ones are not, and then derive the parameter values of the consumers' utility functions (assumed to be nested CES in labor supply and goods, and in polluting and non-polluting goods). We carry out these tasks using a mix of calibration and estimation methods as dictated by the limitations of the data available. All the data come from the "Institut National de la Statistique et des Etudes Economiques" (INSEE), France.

The four groups are identified as "managerial staff", "intermediate-salaried employees", "white-collar workers" and "blue-collar workers". The data covers 117 consumption goods which we aggregate into: non-energy consumption representing non-polluting goods, and energy-related consumption representing polluting goods. The data enables us to determine the groups' earning abilities, their labor supplies and their net-oftax-wages. We estimate the values of the elasticities of substitution between labor supply and consumption goods, and between polluting and non-polluting goods, using

\footnotetext{
${ }^{3}$ Ideally, one would like to allow for more types. The limitations of the data does not allow this, however.
} 
annual data on labor supply and consumption of different goods (energy-related and non-energy) in France for the years 1970-97. There exist other estimates of these parameters in the literature which we will also use. We derive the other parameter values of the posited CES utility function (except for emissions) by calibrating the model for the French economy. We base the calculation of the emissions parameter on the assumption that the social damage of a ton of carbon emissions is 850 French francs. This reflects the 1990 recommendation of a carbon tax of this magnitude by the "Groupe Interministériel sur l'Effet de Serre" - a French Government Commission set up to undertake an economics study of the greenhouse effect. By way of comparison, we also use a different estimate reflecting a much stronger (fivefold) marginal social damage of emissions.

All tax policies are evaluated in light of an iso-elastic social welfare function. We choose the value of the inequality aversion index, which dictates the desired degree of redistribution in the economy, on the basis of the observed degree of redistribution in the existing French tax system. In this, we rely on Bourguignon and Spadaro's (2000) derivation of France's social preferences as revealed through its tax system. We specify 9 different tax regimes and compute the consumption levels, labor supplies, and utilities of the four groups, as well as the supporting optimal taxes, under each. Additionally, we compute a system of uniform lump-sum taxes as our "benchmark" for comparison purposes. Three tax regimes are built around a linear income tax system. In one, no (differential) consumption taxes are levied. In the other two, the polluting good is taxed once at the "Pigouvian" rate and once optimally. Four tax regimes are formed around a general income tax schedule. In one, no (differential) commodity taxes accompany the income tax. The next two constrain the polluting good tax to be linear and set once at the Pigouvian rate and once optimally. The fourth allows for a nonlinear tax on the polluting good. In all these cases, the non-polluting good serves as the numeraire and thus goes untaxed. The last two tax regimes allow for differential lump-sum taxes with 
and without a tax on the polluting good.

Finally, we examine the welfare implications of introducing environmental taxes in the "current French tax system". Whereas the nine tax regimes set the feasible tax instruments optimally, the current system (for 1989) is second-best suboptimal. Comparison between the two procedures, provide insight into the significance of optimality of other tax instruments for the redistributive ramifications of environmental tax policies.

All computations are performed twice; once under the assumption that different individual types have identical preferences and once that they have heterogeneous preferences. Under the first assumption, the tax on the polluting good will have solely an externality-correcting role. ${ }^{4}$ Our preference specification implies that, without emissions, commodity taxes would be redundant in this case. Income taxation (whether general or linear) is all that is needed for optimal tax policy. The efficacy and the role of environmental taxes are thus understood best in this case. Under the second scenario, when individuals differ in taste, differential commodity taxes are useful instruments of tax policy. Consequently, the optimal tax on the polluting good will have two components: one for correcting the pollution and the other for conventional optimal tax objectives.

The optimal tax computations help shed light on a number of policy issues. Specifically, we shall seek to provide answers to the following questions: (i) What is the optimal rate of the environmental tax? In particular, how does the rate differ between the cases in which the environmental tax has solely a Pigouvian role and when it also has a redistributive role? (ii) Who gains and who loses when environmental taxes are introduced? Moreover, how do the losses and gains differ when the tax is solely externality-correcting versus when it has a redistributive role as well? (iii) What are the welfare implications of levying a Pigouvian tax when the tax does in fact have a redistributive role? (iv) To what extent differentiating the environmental tax among different types (i.e. non-

\footnotetext{
${ }^{4}$ See Cremer et al. (1998).
} 
linear commodity taxation) helps the government's redistributive objectives? (v) What are the welfare implications of environmental taxes when the tax system is second-best suboptimal?

\section{The model}

The economy consists of four groups of individuals who differ in earning abilities and may differ in tastes as well. Each person, regardless of his type, is endowed with one unit of time. He has preferences over labor supply, $L$, and two categories of consumer goods: a "non-polluting" good $x$, a "polluting good" $y$, and total level of emissions $E$ in the atmosphere. Emissions are created through the consumption of the polluting good. All consumer goods are produced by a linear technology subject to constant returns to scale in a competitive environment. The producer prices of consumer goods are normalized at one.

All consumer types have nested CES preferences in goods and labor supply and in the two categories of consumer goods. They also have identical elasticities of substitution between leisure and non-leisure goods, $\rho$, and between polluting and non-polluting goods, $\omega$. Differences in tastes, if any, are captured by differences in other parameter values of the posited utility function, i.e. $a^{j}$ and $b^{j} .{ }^{5}$ Assume further that emissions enter the utility function linearly. Denote an individual's wage by $w$ and his gross income by $I=w L$. The preferences for a person of type $j$ can then be represented by

$$
\mho^{j}=\mathbf{U}\left(x, y, \frac{I}{w^{j}} ; \theta^{j}\right)-\phi E, \quad j=1,2,3,4,
$$

where $\theta^{j}$ reflects the "taste parameter" and

\footnotetext{
${ }^{5}$ We impose these restrictions because of the data limitations. Goulder et al. (1999) have used a similar structure for consumer preferences to examine the cost e ectiveness of di erent environmental policies. However, because their model is one of identical consumers, they assume that $a^{j}$ and $b^{j}$ also do not vary across consumers.
} 


$$
\begin{aligned}
\mathbf{U}\left(x, y, \frac{I}{w^{j}}, \theta^{j}\right) & =\left(b^{j} Q^{j \frac{\rho-1}{\rho}}+\left(1-b^{j}\right)\left(1-\frac{I}{w^{j}}\right)^{\frac{\rho-1}{\rho}}\right)^{\frac{\rho}{\rho-1}}, \\
Q^{j} & =\left(a^{j} x^{\frac{\omega-1}{\omega}}+\left(1-a^{j}\right) y^{\frac{\omega-1}{\omega}}\right)^{\frac{\omega}{\omega-1}} .
\end{aligned}
$$

Next, normalize the population size at one and denote the fraction of people of type $j$ to total population by $\pi^{j}$. Total level of emissions is then related to the consumption of the polluting good according to

$$
E=\sum_{j=1}^{4} \pi^{j} y^{j},
$$

Consumers choose their consumption bundles by maximizing (1)-(3) subject to their budget constraints. These may be nonlinear functions as we allow for the possibility that the income tax schedule is nonlinear. We will, however, for the purpose of uniformity in exposition, characterize the consumers' choices, even when they face a nonlinear constraint, as the solution to an optimization problem in which each person faces a (type specific) linearized budget constraint. To do this, introduce a "virtual income" into each type's budget constraint. Denote the $j$-type's marginal income tax rate by $t^{j}$ and let $w_{n}^{j}=w^{j}\left(1-t^{j}\right)$. We can then write $j$ 's budget constraint as

$$
p x^{j}+q y^{j}=M^{j}+w_{n}^{j}\left(\frac{I^{j}}{w^{j}}\right),
$$

where $p$ and $q$ are the consumer prices of $x$ and $y$, and $M^{j}$ consists of the individual's exogenous income plus the income adjustment term (virtual income) needed for linearizing the budget constraint. Note also that $I^{j}=w^{j} L^{j}$ so that $w_{n}^{j}\left(I^{j} / w^{j}\right)=w_{n}^{j} L^{j}$. The first-order conditions for a $j$-type's optimization problem are

$$
\begin{gathered}
\frac{1-a^{j}}{a^{j}}\left(\frac{x^{j}}{y^{j}}\right)^{\frac{1}{\omega}}=\frac{q}{p}, \\
\frac{\left(1-b^{j}\right)\left(x^{j} /\left(1-\frac{I^{j}}{w^{j}}\right)\right)^{\frac{1}{\rho}}}{a^{j} b^{j}\left[a^{j}+\left(1-a^{j}\right)\left(x^{j} / y^{j}\right)^{\frac{1-\omega}{\omega}}\right]^{\frac{\omega-\rho}{\rho(1-\omega)}}}=\frac{w_{n}^{j}}{p} .
\end{gathered}
$$




\section{Types, goods, and the data}

In order to compute the optimal tax rates, we have (i) to identify the consumer types, (ii) to specify which goods are polluting and which ones are not, and (iii) to determine the parameter values of the consumers' utility functions. We carry out these tasks using a mix of calibration and estimation methods as dictated by the limitations of the data available to us. All the data come from the "Institut National de la Statistique et des Etudes Economiques" (INSEE), France.

To identify the types, we use two data sources: "Budget des familles" and "Enquête sur l'emploi". The first are consumption surveys conducted for eight different household types; they are available only for four different years. The second are surveys on employment and wages also classified by household types. These surveys are available on an annual basis starting with 1987. The most recent year for which both data sources are available is 1989. We use this year as the basis for our calibrations. Out of the eight categories, only four report any wage incomes. They are classified as: "managerial staff", "intermediate-salaried employees", "white-collar workers" and "blue-collar workers". They constitute the four types of individuals in our model. The data covers 117 consumption goods which we aggregate into: (i) non-energy consumption representing non-polluting goods $(x)$, and (ii) energy consumption representing polluting goods $(y)$.

The 1989 data also enables us to determine the types' earning abilities; $w^{j}$ 's. We can compute these from data provided on gross wage incomes $\left(I^{j}\right)$ and labor supplies $\left(L^{j}\right)$ using the relationship $w^{j}=I^{j} / L^{j}$. Wage incomes for each of the four household types are reported in INSEE (1991b) on an annual basis for the year 1989. Labor supplies are reported on a weekly basis as "weekly working hours" (WWH) in INSEE (1989). Given that a typical individual in France works for 47 weeks in a year, his hourly wage is equal to $I^{j} / 47 W W H^{j}$. To translate this to a figure for earning ability per year, one must estimate a worker's "time endowment" per year. We assume that each person has 
a time endowment of 16 hours per day, 5 days per week, and 47 weeks per year (he must sleep at least 8 hours a day, have two days off each week, and 5 weeks of vacation per year). We thus multiply $I^{j} / 47 W W H^{j}$ by $47 \times 5 \times 16=3760 .^{6}$ In short, $w^{j}$ is computed according to

$$
w^{j}=\frac{3760 I^{j}}{47 W W H^{j}} .
$$

Additionally, we may compute, for each type, a "net-of-tax-wage" $w_{n}^{j}=\left(1-t^{j}\right) w^{j}$. This is done on the basis of marginal tax rate, $t^{j}$, that type $j$ faces. The marginal tax rates for 1989 are from the French official tax publications (Ministere de l'Economie et des Finances, 1989). Note also that from the figures for $w_{n}^{j}$ and $L^{j}$, we can calculate the value of the $j$-type's virtual income, $M^{j}$, through equation (5). Table 1 provides a summary of the 1989 data.

Next, we must estimate the parameter values of the utility function. The limited (to only four years) time series data on consumption of different types preclude us from estimating the parameters $\rho, \omega, b^{j}$ and $a^{j}$ directly from first-order conditions (6)-(7). In view of this, we proceed as follows.

\subsection{Calculation of $\rho$ and $\omega$}

Starting with $\omega$, there are no econometric studies that estimate the parameter - at least not within the context of dividing goods between polluting and non-polluting and certainly not for the French data. The only reference point for $\omega$ is provided by Goulder et al. (1999). They use a value of 0.85 for this parameter citing an earlier study by Cruz and Goulder (1992) depicting the US economy in 1990. The absence of an estimate for $\omega$ in the literature necessitated our own attempt at estimating it using a French

\footnotetext{
${ }^{6}$ There are other "equally reasonable" estimates for the time endowment, e.g., $52 \times 5 \times 16=4160$, $52 \times 7 \times 16=5824$, or $52 \times 7 \times 18=6552$ (where one assumes 6 hours of sleep). A higher time endowment implies, everything else being equal, a higher uncompensated elasticity of labor supply with respect to wage (through a higher income e ect). We have opted for a lower endowment value so that the generated uncompensated labor supply elasticities correspond to their actual empirical estimates. Note that the compensated wage elasticity is determined via the elasticity of substitution between leisure and non-leisure goods $(\rho)$.
} 
Table 1. Data Summary:1989

(monetary figures in French francs)

\begin{tabular}{|l|rrrr|}
\hline & $\begin{array}{r}\text { Managerial Staff } \\
\text { (Type 1) }\end{array}$ & $\begin{array}{r}\text { Intermediary Level } \\
\text { ((Type 2) }\end{array}$ & $\begin{array}{r}\text { White Collars } \\
\text { (Type 3) }\end{array}$ & $\begin{array}{c}\text { Blue Collars } \\
\text { (Type 4) }\end{array}$ \\
\hline$\pi$ & $15.41 \%$ & $24.77 \%$ & $20.00 \%$ & $39.82 \%$ \\
$p x$ & 254,111 & 174,207 & 127,979 & 128,375 \\
$q y$ & 15,597 & 13,484 & 9,805 & 11,782 \\
$p_{Q} Q=p x+q y$ & 269,708 & 187,691 & 137,783 & 140,156 \\
$p x / p_{Q} Q$ & 0.94217 & 0.92816 & 0.92884 & 0.91594 \\
$q y / p_{Q} Q$ & 0.05783 & 0.07184 & 0.07116 & 0.08406 \\
$L$ & 0.51750 & 0.47000 & 0.45000 & 0.48375 \\
$w$ & 415,156 & 252,215 & 171,938 & 157,972 \\
$t$ & $28.8 \%$ & $19.2 \%$ & $14.4 \%$ & $9.6 \%$ \\
$w_{n}$ & 295,591 & 203,790 & 147,179 & 142,807 \\
$M$ & 116,740 & 91,910 & 71,553 & 71,074 \\
\hline
\end{tabular}

data source. ${ }^{7}$ The OLS estimation of logarithmic transformation of (6), using lagged values of $\ln (x / y)$ and $\ln (q / p)$ also as regressors to correct for autocorrelation, yields an estimate for $\omega$ [the elasticity of substitution between $x$ (non-energy goods) and $y$ (energy goods)] equal to 0.2689 . This is not the only value of $\omega$ that we use; however. For the purpose of sensitivity analysis, we redo all our optimal tax calculations using $\omega=0.99$ (a number even larger than that used by Goulder et al.).

Turning to $\rho$, there are a number of estimates of this parameter in the literature. Stern (1976), in his classic study of an optimal linear income tax system, suggests a value of 0.4 on the basis of estimates for married males in the US. Wales and Woodland (1979) give the estimates of 0.83 and 0.91 (depending on the estimation method) based on PSID data. Goulder et al. (1999) use a value of 0.96. More recently, Bourguignon (1999) observes that the existing estimates for the wage elasticity of labor supply are anywhere between 0.1 and 0.5 . These values can be shown to correspond to a range of estimates

\footnotetext{
${ }^{7}$ This data, given in INSEE (1998), is annual and covers the years 1970-1997 and given both at current and 1980 constant prices. However, it is a macro data; i.e. aggregated over all household types. The estimation thus proceeds as if equations (6)-(7) apply to a "representative" household.
} 
for $\rho$ from to 0.61 to 1.39 ; see the Appendix. We perform all our optimal tax calculations using both of these limiting values. However, for our base calculations, we use a value for $\rho$ that we estimate directly (again through $O L S$ ), so that it is based on the same data set used for the estimation of $\omega$. We derive an estimate of $\rho$ equal to 0.6649 which is within the 0.61 to 1.39 range found in the literature. ${ }^{8}$

\subsection{Calibration of $a^{j}$ and $b^{j}$}

Given the estimates of $\omega$ and $\rho$, we compute $a^{j}$ and $b^{j}$, for $j=1,2,3,4$, on the basis of 1989 INSEE disaggregated data. We calculate the values of $a^{j}$ 's and $b^{j}$ 's numerically as the solution to the non-linear system of equations (6)-(7) using GAUSS. Note that the values of $b^{j}$ depend on both $\rho$ and $\omega$, but the values of $a^{j}$ are independent of $\rho$ (depending on $\omega$ only). Finally, we recompute the values of $a^{j}$ and $b^{j}$ on the assumption that they do not differ across types; i.e. all individual types have identical tastes. This is again done on the basis of equations (6)-(7) using the data aggregated over the four types and weighted in proportion to their size.

\subsection{Calculation of $\phi$}

The starting point for calculation of $\phi$, the coefficient of emissions in the utility function, is a 1990 recommendation of the "Groupe Interministériel sur l'effet de Serre". This was a French Government Commission set up to undertake an economics study of the greenhouse effect. The recommendation called for a carbon tax of 850 French Francs per ton of emitted carbon. We calculate the number of units of the polluting good that would emit one ton of carbon. ${ }^{9}$ We also calculate the cost of producing these many units. Dividing 850 French francs by this latter number, one arrives at the "tax rate" on the polluting good that corresponds to the proposed tax of 850 French franc on a

\footnotetext{
${ }^{8}$ Our estimating equation is the logarithmic transformation of (A2) in the Appendix.

${ }^{9}$ To do this, we calculate the carbon content of a unit of the polluting good (energy-related consumption goods). We do this based on the carbon content of oil, coal, natural gas and electricity, and by calculating their share in energy-related consumption goods.
} 
ton of carbon emissions. This is approximately 10\%. Assuming that 850 French francs measures the social damage of a ton of carbon emissions, the marginal social damage of a unit of polluting good would be $10 \%$ of its cost of production. Now because at the first-best, the optimal tax on a polluting good is its marginal social damage, we calculate $\phi$ in such a way as it would give rise to a first-best tax of $10 \% .{ }^{10}$ We then fix the value of $\phi$ at this estimated value for all the second-best tax calculations. Note that we will have a different value for $\phi$ for each set of parameter values for $\rho, \omega, a^{j}$ and $b^{j}$, $j=1,2,3,4$.

This value of $\phi$ is not the only one we use. There is no general agreement of an "appropriate" measure of the marginal social damage of emissions. To get an idea of the relevance of this for our study, we determine all our optimal tax policies one more time assuming a first-best tax rate of $50 \%$.

\subsection{Government expenditures}

Finally, our optimal tax calculations are based on the assumption that the government's external revenue requirement (expenditures on non-transfer payments) is equal to $20 \%$ of France's GDP at the first-best allocations. This corresponds approximately to the actual value of such expenditures in France.

\section{Tax policies}

The usefulness of environmental taxes must be evaluated in relation to other tax instruments that the government has at its disposal. Of particular interest is the structure of the accompanying income taxes, e.g., linear or nonlinear. The feasibility of a particular tax instrument is ultimately determined by the type of information that is available to

\footnotetext{
${ }^{10}$ Specifying the social welfare function as $\sum_{j} \pi^{j} W\left(\mho^{j}\right)$, the marginal social damage of emissions is defined as $\left[\sum_{j} \pi^{j} W^{\prime}\left(\mho^{j}\right)\right] \phi / \mu$, where $\mu$ is the shadow cost of public funds (the Lagrange multiplier associated with the government's budget constraint); see Section 4 below. This is the formula for the first-best Pigouvian tax.
} 
the tax administration. Public observability of individual incomes typically allows the government to impose nonlinear income taxes. Nevertheless, the income tax literature has traditionally paid a great deal of attention to the study of the linear income taxation. We thus divide the environmental tax polices into those that accompany a linear income and those with a general income tax.

The considered tax policies will be evaluated in light of an iso-elastic social welfare function

$$
W=\frac{1}{1-\eta} \sum_{j=1}^{4} \pi^{j}\left(\mho^{j}\right)^{1-\eta} \quad \eta \neq 1 \quad \text { and } \quad 0 \leq \eta<\infty
$$

where $\eta$ is the "inequality aversion index". The value of $\eta$ dictates the desired degree of redistribution in the economy: The higher is $\eta$ the more the society cares about equality. ${ }^{11}$

In choosing a value for $\eta$ for our optimal tax calculations, we will be guided by the observed degree of redistribution in the existing French tax system. Bourguignon and Spadaro (2000) have recently studied France's social preferences as revealed through its tax system. They find that, if the uncompensated wage elasticity of labor supply is 0.1 , the marginal social welfare falls from 110 to 90 percent of the mean as income increases from the lowest to the highest level. The fall would be from 150 percent to 50 percent if the uncompensated labor elasticity is 0.5 .

With the social welfare function (8), the marginal social utility of income for a $j$-type person is given by

$$
\frac{\partial \mho^{j}}{\partial M^{j}}\left(\mho^{j}\right)^{-\eta}
$$

This implies that the ratio of the marginal social utility of income of the "Managerial Staff" (type 1) to "Blue Collars" (type 4) is

$$
\frac{\partial \mho^{1} / \partial M^{1}}{\partial \mho^{4} / \partial M^{4}}\left(\frac{\mho^{4}}{\mho^{1}}\right)^{\eta}
$$

\footnotetext{
${ }^{11}$ As is well-known, $\eta=0$ implies a utilitarian social welfare function and $\eta \rightarrow \infty$ a Rawlsian.
} 
Calculating the values for $\partial \mho^{j} / \partial M^{j}$ and $\mho^{j}(j=1,4)$ based on the French data summarized in Table 1 , setting the above expression equal to $9 / 11$, we derive a value for $\eta$ equal to 0.1 . This is the implied value for the inequality aversion index in France (if the uncompensated was elasticity of labor supply is 0.1). Similarly, setting the above expression equal to $5 / 15$, we derive a value for $\eta$ equal to 1.9 for the implied value of the inequality aversion index in France (if the uncompensated was elasticity of labor supply is 0.5$)$.

\subsection{The linear income tax}

The procedure for determining the optimal tax policy when the income tax is linear, is to determine the values of the tax parameters that maximize a social welfare function defined in terms of the individuals' indirect utility functions. For this purpose, we first determine the $j$-type's demand functions for nonpolluting and polluting goods, and his labor supply function, from equations (5)-(7). We have

$$
x^{j}=\mathbf{x}\left(p, q, w_{n}^{j}, M^{j} ; \theta^{j}\right) ; y^{j}=\mathbf{y}\left(p, q, w_{n}^{j}, M^{j} ; \theta^{j}\right) ; L^{j}=\mathbf{L}\left(p, q, w_{n}^{j}, M^{j} ; \theta^{j}\right) .
$$

Note that the demand and supply functions for different consumer types will be of different functional forms, when written as functions of $p, q, w_{n}^{j}$ and $M^{j}$, whenever $a^{j}$ and $b^{j}$ differ across types. Finally, using (9), we can derive the $j$-type's indirect utility function: $\mathbf{v}\left(p, q, w_{n}^{j}, M^{j} ; \theta^{j}\right)$.

The government's problem can be specified as one of choosing its tax instruments in order to maximize

$$
\frac{1}{1-\eta} \sum_{j=1}^{4} \pi^{j}\left[\mathbf{v}\left(p, q, w_{n}^{j}, M^{j} ; \theta^{j}\right)-\phi \sum_{j=1}^{4} \pi^{j} \mathbf{y}\left(p, q, w_{n}^{j}, M^{j} ; \theta^{j}\right)\right]^{1-\eta}
$$

subject to its revenue constraint

$$
\sum_{j=1}^{4} \pi^{j}\left[(p-1) x^{j}+(q-1) y^{j}+t w^{j} L^{j}-T\right] \geq \bar{R},
$$


where $t$ is the tax rate and $T$ is the lump-sum tax element of the linear income tax schedule, and $\bar{R}$ is the government's external revenue requirement. Note also that in the absence of any other exogenous income, $T=-M^{j}$.

The full array of tax instruments in the government's optimization problem are: $p-1, q-1, t$ and $T$. However, because the demand functions for goods, and the labor supply function, are all homogeneous of degree zero in $p, q, w_{n}^{j}$ and $M^{j}$, we can, without any loss of generality, set one of the commodity tax rates at zero (one of the consumer prices at one). We will choose the nonpolluting good to be the one whose tax rate is set at zero. That is, we shall set $p=1$ everywhere. Different tax policies are then identified through imposition of different constraints on these instruments and thus on the problem (10)-(11).

We consider four tax policies. The first is one of a uniform lump sum tax (ULST). This serves as our "benchmark" for evaluating other tax regimes. To derive the equilibrium under this policy, we have to impose the additional constraints that $q=1$ and $t=0$ on problem (10)-(11). Consequently, $T$ will be the only available tax instrument. Next, we consider the possibility of levying a linear income tax absent any commodity taxes ( $L I T A C T)$. To find the equilibrium under $L I T A C T$, we impose the constraint $q=1$ on problem (10)-(11). The feasible tax instruments are now only $t$ and $T$. Third, we consider a linear income tax accompanied by a tax on the polluting good equal to its marginal damage $(\operatorname{LITPDT})$. This requires the constraints $q-1=\left[\sum_{j} \pi^{j}\left(\mho^{j}\right)^{-\eta}\right] \phi / \mu$, where $\mu$ is the Lagrangian multiplier associated with the government's budget constraint (11). ${ }^{12}$ Again, the optimizing tax instruments are $t$ and $T$. Finally, we consider a tax regime consisting of a linear income tax in which the polluting good is taxed optimally $(L I T O D T)$. No additional constraints need be imposed on problem (10)-(11); the feasible tax instruments are $t, T$ and $q$.

\footnotetext{
${ }^{12}$ This definition of the "Pigouvian tax" is that of Cremer et al. (1998). Bovenberg and van der Ploeg (1994), and others, define this term di erently. We also calculate the value of the Pigouvian tax based on their definition. This is discussed in more detail at the end of Section 5 .
} 


\subsection{The general income tax}

Next, we consider four other tax regimes formed around a general income tax (where we continue with our normalization rule of setting the tax on the nonpolluting good to be zero; i.e. $p=1$ ). The main complication that arises when one allows for a general income tax is that (in contrast to a linear income tax) one can no longer count on the individuals' incentive compatibility constraints to be satisfied automatically. To ensure that the desired equilibrium satisfies these constraints, one has to impose them on the government's optimization problem directly.

We employ two different procedures depending on the feasibility of nonlinear commodity tax instruments.

\subsubsection{Linear commodity taxes}

Denote $M^{j}+w_{n}^{j} L^{j} \equiv c^{j}$. From equations (5) and (6), determine the demand functions for $x^{j}$ and $y^{j}$ as $x^{j}=\hat{x}\left(p, q, c^{j} ; \theta^{j}\right)$ and $y^{j}=\hat{y}\left(p, q, c^{j} ; \theta^{j}\right)$. Next, derive $c^{j}$ and $I^{j}$ as the solution to the following problem for the government. Maximize

$$
\frac{1}{1-\eta} \sum_{j=1}^{4} \pi^{j}\left[\boldsymbol{U}\left(\hat{x}\left(p, q, c^{j} ; \theta^{j}\right), \hat{y}\left(p, q, c^{j} ; \theta^{j}\right), \frac{I^{j}}{w^{j}} ; \theta^{j}\right)-\phi \sum_{j=1}^{4} \pi^{j} \hat{y}\left(p, q, c^{j} ; \theta^{j}\right)\right]^{1-\eta}
$$

with respect to $c^{j}$ and $I^{j}$, subject to the resource constraint

$$
\sum_{j=1}^{4} \pi^{j}\left(I^{j}-c^{j}+(p-1) x^{j}+(q-1) y^{j}\right) \geq \bar{R}
$$

the incentive compatibility constraints, for $j \neq k ; j, k=1,2,3,4$,

$$
\boldsymbol{U}\left(\hat{x}\left(p, q, c^{j} ; \theta^{j}\right), \hat{y}\left(p, q, c^{j} ; \theta^{j}\right), \frac{I^{j}}{w^{j}} ; \theta^{j}\right) \geq \boldsymbol{U}\left(\hat{x}\left(p, q, c^{k} ; \theta^{j}\right), \hat{y}\left(p, q, c^{k} ; \theta^{j}\right), \frac{I^{k}}{w^{j}} ; \theta^{j}\right)
$$

and an additional constraint that

$$
q=1
$$


Having determined $c^{j}$ and $I^{j}$, and thus $x^{j}$ and $y^{j}$, we can then determine $t^{j}$, the $j$-type's marginal income tax rate required to implement these allocations, from (7). Moreover, if implementation is to be carried out through a menu of linear income tax schedules (possibly truncated), we can calculate the required lump-sum tax to be levied on the $j$-type, $T^{j}\left(=-M^{j}\right)$, from $(5)$.

The first case we examine using this procedure, is when no commodity taxes accompany the general income tax $(G I T A C T)$. This is precisely the solution to the problem (12)-(15). The next two tax regimes we examine, complement a general income tax with a tax on the polluting good: One sets this tax at a Pigouvian level (GITPDT) and the other chooses it optimally $(G I T L D T)$. They are found by following exactly the same procedure as above except that in the former $q$ is set equal to $1+\left[\sum_{j} \pi^{j}\left(\mho^{j}\right)^{-\eta}\right] \phi / \mu$ (instead of 1), and in the latter $q$ is chosen optimally (i.e. constraint (15) is relaxed).

\subsubsection{Nonlinear commodity taxes}

The tax policies considered thus far, have stipulated a tax rate on the polluting good (including zero) which must be the same for all individuals regardless of their type. We next investigate the significance of differentiating this tax amongst the individual types (i.e. levying a nonlinear tax on the polluting good). Whether or not the government can impose nonlinear taxes (on the polluting good or any other good) would of course depend on the structure of public information in the economy. If consumption levels are known at an individual level (i.e. who buys how much), nonlinear commodity taxes are feasible. On the other hand, if the available public information is only on aggregate sales (anonymous transactions), we can only levy linear commodity taxes. While the latter possibility is more realistic for the majority of goods, there exist real examples where individual consumption levels of a polluting good are observable (e.g. electricity). The problem of nonlinear taxation of such goods is thus a relevant policy consideration. Consequently, we will also study a tax regime in which polluting goods may be taxed 
nonlinearly $(G I T N D T)$.

The availability of both a general income and a general commodity tax allows us to derive the optimal allocations directly. This requires finding the solution to the following government problem. Maximize

$$
\frac{1}{1-\eta} \sum_{j=1}^{4} \pi^{j}\left[\boldsymbol{U}\left(x^{j}, y^{j}, \frac{I^{j}}{w^{j}} ; \theta^{j}\right)-\phi \sum_{j=1}^{4} \pi^{j} y^{j}\right]^{1-\eta},
$$

with respect to $x^{j}, y^{j}$ and $I^{j}$, subject to the resource constraint

$$
\sum_{j=1}^{4} \pi^{j}\left(I^{j}-x^{j}-y^{j}\right) \geq \bar{R}
$$

and the self-selection constraints

$$
\boldsymbol{U}\left(x^{j}, y^{j}, \frac{I^{j}}{w^{j}} ; \theta^{j}\right) \geq \boldsymbol{U}\left(x^{k}, y^{k}, \frac{I^{k}}{w^{j}} ; \theta^{j}\right), \quad j \neq k ; j, k=1,2,3,4 .
$$

Having determined the optimal allocations $\left(x^{j}, y^{j}, I^{j}\right)$, one can calculate the (marginal) tax rate on the polluting good, for the $j$-type, from equation (6). This is given by $\left(1 / a^{j}-1\right)\left(x^{j} / y^{j}\right)^{1 / \omega}-1$. Then, $T^{j}$ and $t^{j}$ are determined from equations (5) and (7).

\subsection{First best}

For comparison purposes, we will also calculate two tax regimes in which differential lump-sum taxation is feasible. They differ in their tax treatment of the polluting good. In one, the polluting good goes tax free $(F B A D T)$. This is found by dropping the self-selection constraints (14) in problem (12)-(15) (and then determining $t^{j}$ and $T^{j}$ as previously where the solution for $t^{j}$ should be zero). In the other tax regime, the polluting good is taxed optimally. This is of course the first-best allocations $(F B)$. It is attained by dropping the self-selection constraints (18) in problem (16)-(18) (while determining $q^{j}-1, t^{j}$ and $T^{j}$ as previously). 


\subsection{Welfare comparisons}

Finally, to conduct welfare comparisons, we report equivalent variation, $E V$, of a change in policy from the "benchmark allocation" $B$ to one of the tax "alternatives" discussed. Thus, for each type $j=1,2,3,4$, we calculate an $E V^{j}$ from the following relationship

$$
\mathbf{v}\left(p_{B}, q_{B}, w_{n, B}^{j}, T_{B}^{j}+E V_{i}^{j}\right)-\phi \sum_{j=1}^{4} \pi^{j} y_{B}^{j}=\mathbf{v}\left(p_{i}, q_{i}, w_{n, i}^{j}, T_{i}^{j}\right)-\phi \sum_{j=1}^{4} \pi^{j} y_{i}^{j},
$$

where subscript $B$ denotes the benchmark (ULST) and subscript $i$ refers to one of the tax options: LITACT, LINPDT, LINODT, GITACT, GITPDT, GITLDT, GITNDT, FBADT, and FB. We will then measure the "welfare change" in going from policy $i$ to $k$ by $E V_{k}^{j}-E V_{i}^{j}{ }^{13}$

\section{Optimal taxes with identical tastes}

This section examines the welfare properties of introducing an environmental tax into our first-best and second-best settings. This is based on the assumption that the four types have identical tastes. The efficacy and the role of environmental taxes are understood best in this case. The reason for this is that the tax on the polluting good here will have solely an externality-correcting role. Our specification of preferences in (2)(3) implies that without emissions, commodity taxes are redundant. Income taxation (whether general or linear) is all that is needed for optimal tax policy. [See Atkinson and Stiglitz (1976) and Deaton (1979)].

Throughout the paper, for the sake of brevity, we focus on the results derived for the specification: a marginal social damage of emissions of $10 \%$ (of the unit cost of the polluting good), $\eta=.1, \rho=.6649$, and $\omega=0.2689$. The various simulations we have run reveal that the general pattern of the results and the lessons that emerge are not

\footnotetext{
${ }^{13}$ This is of course di erent from calculating the $E V$ in going "directly" from $i$ to $k$. Whereas this latter concept measures the "monetary equivalent" of the utility change in terms of prices in $i, E V_{k}^{j}-E V_{i}^{j}$ is calculated in terms of $p_{B}$ (regardless of what $k$ and $i$ are). This way, one can compare the welfare change in going from $i$ to $k$ versus, say, $s$ to $l$, in a meaningful manner.
} 
parameter specific. Of course, the actual numbers do vary with the parameter values. However, we will also point out when a parametric specification changes the specifics of a particular result.

\subsection{The first-best environment}

The $F B$ equilibrium is supported by a lump-sum tax of 403,648 and 185,178 francs on types 1 and 2 and a positive grant of 70,634 and 160,310 francs on types 3 and 4 . Additionally, there is a $10 \%$ tax on the polluting good. This latter tax raises 128, 234, 864 and 1,145979 francs from types 1 to 4 . Note that the lower wage persons will pay higher environmental taxes. This reflects the fact that at the first-best solution, lower wage-earners will consume more of all goods, including the polluting good, than the higher wage-earners and thus pay higher taxes too. ${ }^{14}$

The introduction of environmental taxes in a first-best environment results in a redistribution of total tax payments by different households. A comparison of FBADT and $F B$ reveals that total tax payments of types 1 and 2 are increased by 13 and 10 francs while the tax payments of types 3 and 4 are reduced by 4 and 9 francs. These changes are very modest indeed. The welfare implications of the environmental tax can be determined by considering the changes in the $E V$ terms for different types (in moving from $F B A D T$ to $F B$ ). Types 1-4 gain 11, 7, 8 and 11 francs. Obviously, we have a Pareto improving environmental tax, albeit, a modest one. ${ }^{15}$

Table 2 summarizes the welfare gains for different values of the assumed marginal social damage of emissions and the inequality aversion index. Welfare gains remain quite modest as $\eta$ increases. However, as one may expect, environmental taxes result in

\footnotetext{
${ }^{14}$ This result corresponds to the general property that with a utilitarian, or any concave, social welfare function, first-best allocations require the higher wage persons to work more but to receive no more (in after tax pay) than the lower-wage persons. See Stiglitz (1987).

${ }^{15}$ The introduction of an additional instrument (which is not redundant) pushes the utility frontier upwards. However, when the optimum is characterized by the maximum of a particular social welfare function (utilitarian or otherwise), this does not necessarily imply a Pareto improvement. This point should be borne in mind later on also when we discuss other tax policies that are not Pareto improving.
} 
Table 2. Welfare gains of environmental taxes in the first-best

(Identical tastes with $\rho=0.6649, \omega=0.2689$; monetary figures in French francs)

\begin{tabular}{|l|rr|rr|}
\hline & \multicolumn{2}{|c|}{$M S D_{F B}=0.1$} & \multicolumn{2}{c|}{$M S D_{F B}=0.5$} \\
& $\eta=0.1$ & $\eta=1.9$ & $\eta=0.1$ & $\eta=1.9$ \\
\hline Type 1 & 11 & 9 & 0 & 207 \\
Type 2 & 7 & 9 & 38 & 193 \\
Type 3 & 8 & 9 & 239 & 185 \\
Type 4 & 11 & 9 & 343 & 183 \\
\hline
\end{tabular}

significantly higher welfare gains as the marginal social damage of emissions increases.

\subsection{The linear income tax environment}

Observe first that the numerical results for LITPDT is identical to those under LITODT. That is, optimal taxation of the polluting good is equal to levying a Pigouvian tax on it. This is of course due to our specification of preferences. Note, however, that we do not impose this equality as a constraint on our optimization procedure. Rather, the result emerges as the outcome of our different optimization procedures. The optimal tax is now $9.8 \%$. This is smaller than the $10 \%$ under the first best. It reflects the fact that shadow cost of public funds (the Lagrange multiplier associated with the government's revenue constraint) is higher than in the first best. Nevertheless note that the reduction in the optimal tax is very marginal.

The introduction of an environmental tax into a linear income tax system allows the income tax rate to be cut from $18.8 \%$ to $18.4 \%$. On the other hand, the lumpsum tax element of the linear income tax is increased from 4,007 to 4,041 francs. The environmental tax thus allows the government to cut other distortionary taxes in the economy. Its redistributive implications continues to be extremely modest. Types 1 and 2 pay nine and one francs less and types 3 and 4 each pay three francs more in total taxes. In welfare terms, $E V$ figures in going from $L I T A C T$ to $L I T O D T$ indicate gains 
Table 3. Welfare gains of environmental taxes when added to an optimal linear income tax

(Identical tastes with $\rho=0.6649, \omega=0.2689$; monetary figures in French francs)

\begin{tabular}{|l|rr|rr|}
\hline & \multicolumn{2}{|c|}{$M S D_{F B}=0.1$} & \multicolumn{2}{c|}{$M S D_{F B}=0.5$} \\
& $\eta=0.1$ & $\eta=1.9$ & $\eta=0.1$ & $\eta=1.9$ \\
\hline Type 1 & 17 & 14 & 353 & 315 \\
Type 2 & 10 & 9 & 204 & 193 \\
Type 3 & 5 & 6 & 122 & 127 \\
Type 4 & 5 & 5 & 106 & 115 \\
\hline
\end{tabular}

of $17,10,5$ and 5 francs for types 1 to 4 . While, per household, these are clearly modest gains, it is interesting to note that the introduction of the environmental tax makes all household types better off. The tax is Pareto improving. The gains improve only as a result of huge increases in the marginal social damage of emissions. See Table 3

\subsection{The general income tax environment}

Now consider the introduction of an environmental tax into a general income tax framework. We again note that, due to our preferences specification, our different solution methods result in an optimal environmental tax which is Pigouvian (and thus linear). The optimal tax is $9.96 \%$. It is, as with the linear income tax case, less than its value in the first-best. However, the reduction is even less than under a linear income tax. The point is that the under an optimal general income tax, the shadow cost of public funds is only marginally higher than it is in the first-best. ${ }^{16}$ The environmental tax allows "other" distortionary taxes (now consisting of the marginal income tax rates on all types) to be cut. The marginal tax rate of types 2 to 4 are reduced from to $17.1 \%$ to $16.6 \%$, from $24.1 \%$ to $23.6 \%$ and from $4.3 \%$ to $3.7 \%$. Additionally, the marginal tax rate of type 1 goes to zero. This is as expected reflecting the famous no distortion at the top result.

\footnotetext{
${ }^{16}$ For a theoretical examination, see Boadway and Keen (1994) and Kaplow (1996).
} 


\section{Table 4. Welfare gains of environmental taxes when added to an optimal general income tax}

(Identical tastes with $\rho=0.6649, \omega=0.2689$; monetary figures in French francs)

\begin{tabular}{|l|rr|rr|}
\hline & \multicolumn{2}{|c|}{$M S D_{F B}=0.1$} & \multicolumn{2}{c|}{$M S D_{F B}=0.5$} \\
& $\eta=0.1$ & $\eta=1.9$ & $\eta=0.1$ & $\eta=1.9$ \\
\hline Type 1 & 14 & 10 & 299 & 287 \\
Type 2 & 10 & 9 & 197 & 194 \\
Type 3 & 7 & 9 & 143 & 146 \\
Type 4 & 6 & 7 & 128 & 131 \\
\hline
\end{tabular}

Turning to redistributive implications, the changes in total tax payments continue to be very modest. Payments of types 1 and 2 are reduced by five and one francs while those of types 3 and 4 are increased by two francs each. To gauge the welfare implications of these changes, consider what happens to the various $E V$ terms as we go from GIT ACT to GITPDT. They indicate gains of 14, 10, 7 and 6 francs for types 1 to 4. The environmental tax is thus Pareto improving in this setting as well. We also note that the gains for each household type is very similar to the gains under a linear income tax. It appears that the welfare gains due to environmental taxes do not depend on whether the government employs a linear or a general income tax to achieve its optimal tax objectives. And, as before, the welfare gains improve only as the marginal social damage of emissions increase. See Table 4.

Finally, other simulations reveal that variations in $\rho$, the elasticity of substitution between labor supply and other goods, and $\omega$, the elasticity of substitution between polluting and non-polluting goods, have no perceptible impact on the size of the optimal environmental tax. As to the welfare gains, variations in $\rho$ continue to exert no influence. On the other hand, an increase in $\omega$ increases the size of the welfare gains for all types. This makes sense in that the higher is $\omega$, the higher will be the reduction in emissions as result of a tax on the polluting good and thus a higher welfare gain. 
Table 5. Optimal environmental tax versus sum of private costs of environmental damage

(Identical tastes with $\rho=0.6649, \omega=0.2689$ )

\begin{tabular}{|cc|cc|cc|}
\hline & & \multicolumn{2}{|c|}{$M S D_{F B}=0.1$} & \multicolumn{2}{c|}{$M S D_{F B}=0.5$} \\
& $\eta=0.1$ & $\eta=1.9$ & $\eta=0.1$ & $\eta=1.9$ \\
\hline \multirow{2}{*}{ Linear income tax: } & Optimal tax & $9.83 \%$ & $9.67 \%$ & $49.15 \%$ & $48.32 \%$ \\
& $\phi \sum_{j} \pi^{j} / \alpha^{j}$ & $9.27 \%$ & $8.49 \%$ & $46.40 \%$ & $42.52 \%$ \\
\hline \multirow{2}{*}{ General income tax: } & Optimal tax & $9.96 \%$ & $9.92 \%$ & $49.78 \%$ & $49.58 \%$ \\
& $\phi \sum_{j} \pi^{j} / \alpha^{j}$ & $9.61 \%$ & $9.26 \%$ & $48.08 \%$ & $46.34 \%$ \\
\hline
\end{tabular}

We close this section by making one final observation. It relates to the concept of "the Pigouvian tax". Our discussion of the Pigouvian tax and its equality to the optimal environmental tax, given our specification of preferences, is based on Cremer et al.'s (1998) definition of the Pigouvian tax. According to this definition, a tax is called Pigouvian if it is equal to the marginal social damage of pollution, as measured by $\left[\sum_{j} \pi^{j}\left(\mho^{j}\right)^{-\eta}\right] \phi / \mu$. Bovenberg and van der Ploeg (1994), Bovenberg and de Mooij (1994), Kaplow (1996), Fullerton (1997) and others define the Pigouvian tax differently. Their definition is based on the Samuelson's rule for optimal provision of public goods. They term a tax Pigouvian if it is equal to the sum of the private dollar costs of the environmental damage per unit of the polluting good across all households. In our notation, their Pigouvian tax is $\sum_{j} \pi^{j} \phi / \alpha^{j}$, where $\alpha^{j}$ is the $j$-type's private marginal utility of income. To see how the optimal environmental tax compares with this conception of the Pigouvian tax, we calculate the values for this alternative definition. These are shown in Table 5 and compared with the corresponding optimal environmental taxes.

In every single case reported, the optimal environmental tax is larger than the Pigouvian tax. Indeed, this result is robust and holds in all the tax solutions derived for the various values of $\rho$ and $\omega$ we have considered. This finding may appear surprising in light of Bovenberg and de Mooij's (1994) result that the optimal environmental tax must be 
lower than the Pigouvian tax. However, it does not, technically, contradict their claim which was derived for a representative-consumer economy. ${ }^{17}$ The importance of our finding is that it occurs under an empirically relevant optimal tax scheme. It indicates that, as a policy prescription, one may not be able to rely on Bovenberg and de Mooij's result.

\section{Optimal taxes with heterogeneous tastes}

We now turn to the case when individuals have heterogeneous tastes. Under this circumstance, differential commodity taxes are useful instruments of tax policy. Consequently, the optimal tax on the polluting good will have two components: one for correcting the pollution and the other for conventional optimal tax objectives. Failure to understand this point may result in wrong policy recommendations. ${ }^{18}$

\subsection{The first-best environment}

As with the homogeneous taste case, we start by calculating the welfare gains associated with the introduction of an environmental tax for $\eta=0.1$ and 1.9 and for a marginal social damage of emissions equal to $10 \%$ and $50 \%$ of the unit production cost of the polluting good. The picture that emerges is very much the same as with the case with identical tastes. The only difference appears to be that the tax is no longer always Pareto-improving. However, the tax always enhances the welfare of Type 4, the least well-off persons. [The figures are reported in Table 2a in the Appendix.] Next, we turn to second-best settings, beginning with the linear income tax.

\footnotetext{
${ }^{17}$ See Cremer et al. (2001) for a detailed discussion of Bovenberg and de Mooij's (1994) result.

${ }^{18}$ The redistributive properties of environmental taxes arise because di erent ability types have di erent marginal rates of substitution between polluting and nonpolluting goods at the same consumption and income bundles. In our setup, this is due to our taste-heterogeneity assumption. The same property holds also in a setup with taste homogeneity as long as preferences are nonseparable in labor supply and other goods. Whether this is the case or not, we do not have enough data to even attempt to estimate it. If indeed it were the case that all types have the same underlying, nonseparable and nonhomothetic preferences, one may interpret our setup and results as an "approximation" to it.
} 
Table 6. Optimal versus Pigouvian taxes and their welfare gains when added to an optimal linear income tax

(Heterogeneous tastes with $\rho=0.6649, \omega=0.2689$; monetary figures in French francs)

\begin{tabular}{|l|rr|rr||rr|rr|}
\hline & \multicolumn{4}{|c||}{$M S D_{F B}=0.1$} & \multicolumn{4}{c|}{$M S D_{F B}=0.5$} \\
& \multicolumn{2}{|c}{$\eta=0.1$} & \multicolumn{2}{c||}{$\eta=1.9$} & \multicolumn{2}{c|}{$\eta=0.1$} & \multicolumn{2}{c|}{$\eta=1.9$} \\
& Optimal & Pigouvian & Optimal & Pigouvian & Optimal & Pigouvian & Optimal & Pigouvian \\
\hline Tax rate & $3.16 \%$ & $9.93 \%$ & $-12.48 \%$ & $9.87 \%$ & $40.38 \%$ & $49.64 \%$ & $18.85 \%$ & $49.38 \%$ \\
\hline Type 1 & 84 & 252 & -318 & 207 & 1,257 & 1,451 & 553 & 1,196 \\
Type 2 & 2 & 3 & -27 & -2 & 173 & 172 & 107 & 144 \\
Type 3 & 4 & 7 & -42 & 15 & 127 & 134 & 108 & 179 \\
Type 4 & -25 & -82 & 86 & -81 & -234 & -302 & -80 & -286 \\
\hline
\end{tabular}

\subsection{The linear income tax environment}

Optimal and Pigouvian taxes are now markedly different. This is because with heterogeneous tastes we are no longer in the Atkinson and Stiglitz's world. ${ }^{19}$ Environmental taxes will now have a redistributive function in addition to their Pigouvian role. Moreover, in every single case, the optimal tax turns out to be much smaller than the Pigouvian tax. It is apparent that optimal tax objectives calls for a subsidy on polluting goods (relative to non-polluting goods). Indeed, under some scenarios, optimal taxation calls for an outright subsidy on the polluting goods. Note also as $\eta$ increases the rate of subsidy on the polluting goods relative to non-polluting goods increases. That is, the more we care about equality the more we want to subsidize polluting goods. See Table 6 .

Turning to the welfare gains, one finds that the gains and losses, particularly to Types 1 and 4, are now more substantial (compared to the corresponding figures when consumers had identical tastes). This reflects the redistributive potential of environmental taxes when preferences are heterogeneous. These are presented in Table 6 where

\footnotetext{
${ }^{19}$ Of course, the same is true if preferences are identical but preferences are not weakly separable in labor supply and other goods.
} 
Table 7. Optimal nonlinear environmental taxes in the presence of an optimal general income tax (Heterogeneous tastes with $\rho=0.6649, \omega=0.2689$

\begin{tabular}{|l|rr|rr|}
\hline & \multicolumn{2}{|c|}{$M S D_{F B}=0.1$} & \multicolumn{2}{c|}{$M S D_{F B}=0.5$} \\
& $\eta=0.1$ & $\eta=1.9$ & $\eta=0.1$ & $\eta=1.9$ \\
\hline Type 1 & $10.00 \%$ & $10.00 \%$ & $50.00 \%$ & $50.00 \%$ \\
Type 2 & $-0.27 \%$ & $-17.26 \%$ & $36.15 \%$ & $12.76 \%$ \\
Type 3 & $11.23 \%$ & $12.34 \%$ & $51.66 \%$ & $53.25 \%$ \\
Type 4 & $3.82 \%$ & $-7.32 \%$ & $41.71 \%$ & $26.37 \%$ \\
\hline
\end{tabular}

the welfare gains associated with Pigouvian taxes are also shown. Interestingly, the high-income people gain more under Pigouvian taxes than under optimal taxes. The reverse is true for the least well-off persons who lose more under Pigouvian taxes than under optimal taxes. Additionally, the gains to Type 1 and losses to Type 4 both go down as $\eta$ increases (the society cares more about equality).

\subsection{General income plus linear commodity taxes}

The nature of optimal (linear) environmental taxes in the presence of an optimal general income tax is similar to their pattern in the presence of an optimal linear income tax. The redistributive role of commodity taxes continue to call for a sizable subsidy on polluting goods relative to non-polluting goods with the subsidy rate increasing in $\eta$. Similarly, the welfare properties of optimal and Pigouvian taxes mimic those in the presence of a linear income tax. In particular, Pigouvian taxes entail more gains for the wealthy and less for the poor in comparison to optimal environmental taxes. Moreover, one again finds that the gains to Type 1 and losses to Type 4 both go down as $\eta$ increases. [See Table 6a in the Appendix.]

\subsection{General income plus nonlinear commodity taxes}

Finally, consider levying environmental taxes that are nonlinear. These are presented in Table 7. In all cases, Type 1 people face only a Pigouvian tax (i.e. the environmental 
Table 8. Welfare gains of nonlinear over linear environmental taxes in the presence of an optimal general income tax

(Heterogeneous tastes with $\rho=0.6649, \omega=0.2689$; monetary figures in French francs)

\begin{tabular}{|l|rr|rr|}
\hline & \multicolumn{2}{|c|}{$M S D_{F B}=0.1$} & \multicolumn{2}{c|}{$M S D_{F B}=0.5$} \\
& $\eta=0.1$ & $\eta=1.9$ & $\eta=0.1$ & $\eta=1.9$ \\
\hline Type 1 & -940 & -826 & $-1,154$ & $-1,018$ \\
Type 2 & 1 & 36 & 1 & 44 \\
Type 3 & 34 & 31 & 42 & 37 \\
Type 4 & 344 & 315 & 420 & 385 \\
\hline
\end{tabular}

tax embodies no optimal tax objective). This is to be expected; it reflects the "no distortion at the top" result of the optimal tax theory. The other Types face either a tax or a subsidy. Turning to the welfare gains of nonlinear environmental taxes, both the gains and losses are more substantial than with linear environmental taxes. They also entail more welfare gains on the part of low-income groups and less on the part of highincome groups (compared with linear environmental taxes). Table 8 shows different Type's gains and losses as a result of differentiating environmental tax according to Types (i.e. if we move from a system of linear to nonlinear environmental taxes). The poor gains at the expense of the rich and rather substantially. Evidently, the nonlinear tax on the polluting good, and nonlinear commodity taxation in general, is a powerful redistributive mechanism. ${ }^{20}$

We end our discussion by making one final observation regarding the implication of changing $\rho$ and $\omega$. As previously, only the latter affects the environmental tax rate. Specifically, the optimal environmental tax (in the presence of both a linear and a general income tax) increases with $\omega$. The reason is that as $\omega$ increases the efficiency cost of a potential tax differential between polluting and non-polluting goods increases. This reduces the optimal rate of subsidy on polluting goods due to redistributive considera-

\footnotetext{
${ }^{20}$ Welfare gains of nonlinear environmental taxes over the no tax solution are given in Table $8 \mathrm{a}$ in the Appendix.
} 
Table 9. Welfare gains of environmental taxes when levied in the "Current French Tax system" ( monetary figures in French francs)

\begin{tabular}{|c|c|c|c|c|c|c|c|c|}
\hline & \multicolumn{4}{|c|}{ A $10 \%$ tax } & \multicolumn{4}{|c|}{ A $50 \%$ tax } \\
\hline & \multicolumn{2}{|c|}{$\eta=0.1$} & \multicolumn{2}{|c|}{$\eta=1.9$} & \multicolumn{2}{|c|}{$\eta=0.1$} & \multicolumn{2}{|c|}{$\eta=1.9$} \\
\hline & $\begin{array}{c}\text { Identical } \\
\text { tastes }\end{array}$ & $\begin{array}{c}\text { Hetero- } \\
\text { geneous } \\
\text { tastes }\end{array}$ & $\begin{array}{c}\text { Identical } \\
\text { tastes }\end{array}$ & $\begin{array}{c}\text { Hetero- } \\
\text { geneous } \\
\text { tastes }\end{array}$ & $\begin{array}{c}\text { Identical } \\
\text { tastes }\end{array}$ & $\begin{array}{c}\text { Hetero- } \\
\text { geneous } \\
\text { tastes }\end{array}$ & $\begin{array}{c}\text { Identical } \\
\text { tastes }\end{array}$ & $\begin{array}{c}\text { Hetero- } \\
\text { geneous } \\
\text { tastes }\end{array}$ \\
\hline Type 1 & 511 & 1,282 & 327 & 1,268 & 3,367 & 5,372 & 3,076 & 5,317 \\
\hline Type 2 & -190 & 162 & -182 & 160 & 593 & 917 & 578 & 909 \\
\hline Type 3 & -309 & -4 & -246 & -4 & 77 & 263 & 143 & 264 \\
\hline Туре 4 & -268 & -178 & -249 & -176 & -134 & -443 & -103 & -434 \\
\hline
\end{tabular}

tions. In the identical tastes case, when the environmental tax reflects only Pigouvian considerations, its optimal value was invariant to changes in $\omega$.

\section{The current French tax system}

Thus far, we have examined the welfare implications of environmental taxes where the accompanying income taxes are set optimally. The current income tax structure in France is of course not optimal. Nor will the income taxes be adjusted optimally as a result of introduction of environmental taxes. This section examines the welfare implications of introducing environmental taxes in a suboptimal tax system. The undertaking provides insight into the redistributive implications of environmental taxes if one fails to make offsetting adjustments in the other taxes in the system.

We calculate the welfare gains and losses that accrue to our four Types on the basis of both a $10 \%$ and a $50 \%$ tax on polluting goods. This will be an additional tax on top of the existing taxes on energy consumption in France. The generated tax revenues are rebated lump-sum to consumers in such a way as to keep each Type's current tax shares unchanged. ${ }^{21}$ The results are reported in Table 9. The fascinating feature of these

\footnotetext{
${ }^{21}$ The "current tax system" we use di ers from the actual tax system in France in one aspect. The
} 
results is that they invariably indicate substantial welfare gains for the highest income group and a sizable loss for the least well-off persons. The gains and losses dominate our previous calculations when we had optimal income taxes. The lesson is clearcut. Environmental taxes are regressive. And unless income taxes are adjusted to correct this inherent regressivity, their imposition will hurt the poor and benefit the rich.

\section{Conclusion}

This paper has constructed a model with four different groups of households who have preferences over labor supply, consumption of polluting (energy related) and nonpolluting (non-energy) goods and emissions. It has quantified the model for the French economy and has computed its optimal tax equilibria under nine second-best tax regimes. It has also considered the "current French tax system" which is second-best suboptimal. In doing so, it has attempted to shed light on a number of questions concerning the properties of optimal environmental taxes. In particular, it has shown that: (i) When environmental taxes play a Pigouvian role only, they are to be levied at a rate slightly below their first-best value. When these taxes have a redistributive role as well, they should be set at a rate much below their marginal social damage. That is, they must be subsidized relative to non-polluting goods. Moreover, depending on how much the society values equality, one may want to give polluting goods an outright subsidy (rather than a tax) despite their environmental damage. (ii) All types gain when the environmental tax has solely a Pigouvian role; the welfare gains are rather modest. The gains and losses, particularly to the highest and least well-off persons, become more substantial when environmental taxes have a redistributive role as well. (iii) Setting the environmental tax at its Pigouvian level, rather than its optimal externality-correcting-

various tax systems we have computed have been built around the assumption that consumers have only labor incomes. However, in reality, every consumer type has some nonlabor income. Consequently, to make the results for the "current system" comparable with our optimized tax systems, we have purged each type's nonlabor income from our computation of the "current system". 
cum-redistributive level benefits the high-income group at the cost to the low-income groups. (iv) The welfare gains and losses of nonlinear environmental taxes are more substantial in comparison with linear environmental taxes. They also entail more welfare gains on the part of low-income groups and less on the part of high-income groups (compared with linear environmental taxes). Evidently, nonlinear taxation of polluting goods, and nonlinear commodity taxation in general, is a powerful redistributive mechanism. (v) Introducing environmental taxes in the current French tax system, where the income taxes are suboptimal, results in substantial welfare gains for the highest income group and a sizable loss for the least well-off persons. The gains and losses dominate those under optimal income taxes. This indicates that optimal income taxes help correct the regressive bias of environmental taxes. Without this adjustment, imposition of environmental taxes will hurt the poor and benefit the rich.

These findings are, of course, not meant to be the last word on such important policy question as the taxation of energy. The research can be extended in a number of directions. One may examine different preference structures and a more disaggregated set of goods. In particular, it would be enlightening to compute the optimal tax structures for a model consisting of a greater number of types than four. This needs more extensive data; maybe one can find it for other countries. 


\section{Appendix}

Computing $\rho$ on the basis of wage elasticities: Assume that individuals choose their optimal allocations on the basis of a "two-stage" optimization process. In the first stage, one chooses $Q$ and $L$ to maximize (2) subject to

$$
p_{Q} Q=w_{n} L+M
$$

where $p_{Q}$ is the "price" of $Q$ and we have used (5). In the second stage, one allocates $Q$ between consumption of $x$ and of $y$. The first-order condition for this problem is

$$
\frac{1-b}{b}\left(\frac{Q}{1-L}\right)^{\frac{1}{\rho}}=\frac{w_{n}}{p_{Q}} \text {. }
$$

Substituting for $Q$ from (A1) in above and solving for $L$, we have

$$
L=\frac{1-A M w_{n}^{-\rho}}{1+A w_{n}^{1-\rho}},
$$

where

$$
A \equiv\left(\frac{1-b}{b}\right)^{\rho} p_{Q}^{\rho-1}
$$

From (A3), we the derive the elasticity of labor supply as

$$
\epsilon_{L L} \equiv \frac{w_{n}}{L} \frac{\partial L}{\partial w_{n}}=\frac{\rho M}{w_{n}^{\rho} / A-M}-\frac{1-\rho}{w_{n}^{\rho-1} / A+1} .
$$

Substituting for $A$ in terms of $L$ from (A3) in above, we can rewrite $\epsilon_{L L}$ as

$$
\begin{aligned}
\epsilon_{L L} & =\frac{\rho M}{\left(w_{n} L+M\right) /(1-L)-M}-\frac{1-\rho}{\left(w_{n} L+M\right) / w_{n}(1-L)+1}, \\
& =\frac{1-L}{w_{n}+M}\left[\frac{\rho M}{L}-(1-\rho) w_{n}\right] .
\end{aligned}
$$

Equation (A5) governs the relationship between $\rho$ and $\epsilon_{L L}$. Given any value for $\epsilon_{L L}$, one can compute the corresponding value of $\rho$ for every individual type. This yields a range of values for $\rho$ from 0.61 to 1.39 . 
Table 2a. Welfare gains of environmental taxes in the first-best (Heterogenous tastes with $\rho=0.6649, \omega=0.2689$; monetary figures in French francs)

\begin{tabular}{|l|rr|rr|}
\hline & \multicolumn{2}{|c|}{$M S D_{F B}=0.1$} & \multicolumn{2}{c|}{$M S D_{F B}=0.5$} \\
& $\eta=0.1$ & $\eta=1.9$ & $\eta=0.1$ & $\eta=1.9$ \\
\hline Type 1 & 7 & 8 & -82 & 184 \\
Type 2 & 3 & 9 & -16 & 196 \\
Type 3 & -5 & 8 & -60 & 186 \\
Type 4 & 22 & 9 & 596 & 203 \\
\hline
\end{tabular}

Table 6a. Optimal versus Pigouvian taxes and their welfare gains when added to an optimal general income tax

(Heterogeneous tastes with $\rho=0.6649, \omega=0.2689$; monetary figures in French francs)

\begin{tabular}{|c|rrrr||rr|rr|}
\hline & \multicolumn{4}{|c||}{$M S D_{F B}=0.1$} & \multicolumn{4}{c|}{$M S D_{F B}=0.5$} \\
& \multicolumn{2}{|c}{$\eta=0.1$} & \multicolumn{2}{c||}{$\eta=1.9$} & \multicolumn{2}{c|}{$\eta=0.1$} & \multicolumn{2}{c|}{$\eta=1.9$} \\
& Optimal & Pigouvian & Optimal & Pigouvian & Optimal & Pigouvian & Optimal & Pigouvian \\
\hline Tax rate & $3.62 \%$ & $10.00 \%$ & $-8.11 \%$ & $10.00 \%$ & $41.47 \%$ & $50.00 \%$ & $25.38 \%$ & $50.00 \%$ \\
\hline Type 1 & 102 & 268 & -215 & 232 & 1,274 & 1,473 & 752 & 1,293 \\
Type 2 & 10 & 23 & -31 & 18 & 253 & 268 & 182 & 243 \\
Type 3 & 4 & 6 & -22 & 12 & 147 & 151 & 137 & 182 \\
Type 4 & -34 & -98 & 67 & -95 & -282 & -359 & -137 & -335 \\
\hline
\end{tabular}

Table 8a. Welfare gains of nonlinear environmental taxes when added to an optimal general income tax (Heterogeneous tastes with $\rho=0.6649, \omega=0.2689$; monetary figures in French francs)

\begin{tabular}{|l|rr|rr|}
\hline & \multicolumn{2}{|c|}{$M S D_{F B}=0.1$} & \multicolumn{2}{c|}{$M S D_{F B}=0.5$} \\
& $\eta=0.1$ & $\eta=1.9$ & $\eta=0.1$ & $\eta=1.9$ \\
\hline Type 1 & -838 & $-1,041$ & 120 & -266 \\
Type 2 & 11 & 5 & 254 & 226 \\
Type 3 & 38 & 9 & 189 & 174 \\
Type 4 & 310 & 382 & 138 & 248 \\
\hline
\end{tabular}




\section{References}

Atkinson, A.B. and J.E. Stiglitz (1976) "The design of tax structure : direct versus indirect taxation," Journal of Public Economics, 6, 55-75.

Bourguignon, F. (1999) "Redistribution and labor-supply incentives", mimeo.

Bourguignon, F. and A. Spadaro (2000) "Social preferences revealed through effective marginal tax rates," mimeo.

Bovenberg, A.L. and F. van der Ploeg (1994) "Environmental policy, public finance and the labor market in a second-best world," Journal of Public Economics, 55, 349-390.

Bovenberg, A.L. and R.A. de Mooij (1994) "Environmental Levies and Distortionary Taxation," American Economic Review, 84, 1085-1089.

Bovenberg, A.L. and L. Goulder (1996) "Optimal environmental taxation in the presence of other taxes: general equilibrium analyses," American Economic Review, 86, 985-1000.

Cremer, H., Gahvari, F. and N. Ladoux (1998) "Externalities and optimal taxation," Journal of Public Economics, 70, 343-364.

Cremer, H., Gahvari, F. and N. Ladoux (2001) "Second-best pollution levies and the structure of preferences," Southern Economic Journal, 68, 258280.

Cruz, M. and L.H. Goulder (1992) "An intertemporal general equilibrium mode for analyzing U.S. energy and environmental policies: data documentation," Unpublished manuscript, Stanford University.

Deaton, A. (1979) "Optimally uniform commodity taxes," Economics Letters, 2, 357-361.

Fullerton, D. (1997) "Environmental Levies and Distortionary Taxation: Comment," American Economic Review, 87, 245-251.

Gahvari, F. (2002, forthcoming) "Review of Ruud A. de Mooij: Environmental Taxation and the Double Dividend," Journal of Economic Literature, 40, 221-223.

Goulder, L.H., Parry, I.W.H., Williams III, R.C. and D. Burtraw (1999) "The cost effectiveness of alternative instruments for environmental protection in a second-best setting," Journal of Public Economics, 72, 329360.

Goulder, L.H. (1995) "Environmental taxation and double dividend: A reader's guide," International Tax and Public Finance, 2, 157-183.

INSEE (1989) "Emplois-revenus: enqute sur l'emploi de 1989, rsultats dtaills," Srie INSEE Rsultats, 28-29, ISBN 2-11-065325-6. 
INSEE (1991a) "Consommation modes de vie: le budget des mnages en 1989," Srie Consommation Modes de Vie, 116-117, ISBN 2-11-065922$\mathrm{X}$.

INSEE (1991b) "Emplois-revenus: les salaires dans l'industrie, le commerce et les services en 1987-1989," Srie INSEE Rsultats, 367-369, ISBN 2-1106-244-1.

INSEE (1998) "Comptes et indicateurs conomiques: rapport sur les comptes de la nation 1997," Srie INSEE Rsultats, 165-167, ISBN 2-11-0667748-6.

Kaplow, L. (1996) "The optimal supply of public goods and the distortionary cost of taxation," National Tax Journal, 49, 513-533.

Mayeres, I., and S. Proost (1997) "Optimal tax and public investment rules for congestion type of externalities," Scandinavian Journal of Economics, 99, 261-279.

Mayeres, I., and S. Proost (2001) "Marginal tax reform, externalities and income distribution," Journal of Public Economics, 79, 343-363.

Ministre de l'Economie et des Finances (1989) "Publication N 2041 S," France.

Pirttil, J. and M. Tuomala (1997) "Income tax, commodity tax and environmental policy," International Tax and Public Finance, 4, 379-393.

Poterba, J.M. (1991) "Tax policy to combat global warming: on designing a carbon tax," in Global Warming: Economic Policy Responses, ed. Dornbusch, R. and J.M. Poterba. Cambridge, Massachusetts: The MIT Press.

Saez, E. (2000) "Optimal income transfer programs: intensive versus extensive labor supply responses," mimeo.

Stern, N.H. (1976) "On the specification of models of optimumincome taxation," Journal of Public Economics, 6, 123-162.

Stiglitz, J.E. (1987) "Pareto efficient and optimal taxation and the new new welfare economics," in Handbook of Public Economics Vol 2, 